\title{
Role of the Americans with Disabilities Act in Parental Rights Court Cases
}

\author{
Miranda Sue terry \\ Stephen F. Austin State University, Nacogdoches, U.S.A
}

\begin{abstract}
In this paper, media provides a means of thinking critically about the role of ADA regulations should play in parental rights for individuals with mental disabilities, specifically mental illness, developmental disabilities, and brain injuries. Congress passed the Americans with Disabilities Act more than 20 years ago to ensure the rights of individuals with disabilities, including parental rights. Title II of the ADA applies to decisions made in the courtroom and other governmental agencies, which include child custody cases and termination of parental rights. "Reasonable Accommodations" is one requirement of the ADA to make society more inclusive for individuals with disabilities, even in the realm of parenting. Under Title II, such modifications would include parenting classes, homecare assistance, support groups, community resources, and counseling. Through a critical examination of experiences as depicted through media and court case analyses of parents with mental disabilities, this paper argues that challenging the idea that individuals with disabilities cannot or should not be parents must start in the courtroom, by changing the attitudes and perceptions of judges presiding over child custody cases and termination of parental rights cases involving parents with mental disabilities.
\end{abstract}

Keywords: Americans with Disabilities Act, parental rights, court cases, people with disabilities

\section{Introduction}

Lightfoot and colleagues conducted legal document analysis on the 2005 state codes of all 50 states in the United States and the District of Columbia finding that termination of parental rights can occur based on disability-related issues in 37 states, which is a direct violation of the Americans with Disabilities Act . In 2012, the National Council on Disability released a groundbreaking policy study titled, "Rocking the Cradle: Ensuring the Rights of Parents with Disabilities and Their Children". The first report of its kind to promote the rights of parents with disabilities was much needed in light of the findings of Lightfoot and colleagues. In this paper, media will provide a means of thinking critically about the role ADA regulations should play in parental rights for individuals with mental disabilities, specifically mental illness, developmental disabilities, and brain injuries. Through a critical examination of experiences as depicted through media and court case analyses of parents with mental disabilities, this paper will argue that challenging the idea that individuals with disabilities cannot or should not be parents must start in the courtroom, by changing the attitudes and perceptions of judges presiding over child custody cases and termination of parental rights cases involving parents with mental

Miranda Sue Terry, Assistant professor, Department of Kinesiology and Health Science, Stephen F. Austin State University.

Correspondence concerning this article should be addressed to Miranda Sue Terry, P.O. Box 13015, SFA Station, HPE Bldg, Room 217,Nacogdoches, TX 75962. Email: terryms@sfasu.edu. 
disabilities.

\section{Background: Stigma and Parents with Disabilities}

Emerging in the1980s, disability studies is an interdisciplinary field that takes as its main project a shift away from the medical model and a focus on culture. Influential disability studies scholar, Rosemarie Garland-Thomson sums the reason for this shift up perfectly, "The meanings attributed to extraordinary bodies reside not in inherent physical flaws, but in social relationships in which one group is legitimated by possessing valued physical characteristics and maintains its ascendancy and its self-identity by systematically imposing the role of cultural or corporeal inferiority on others” (Straus, 2010). Disability Studies have brought issues to light concerning people with disabilities and their rights; for example, scholars have noted that parents have acted as advocates for their child with a disability; but what happens when the person with a disability is the parent, especially a mental disability, including mental illness? There appears to be very few support groups or resources for parents with disabilities and very little literature in this area within disability studies; however, there are articles on the clinical side exploring the topic of parents with disabilities, specifically mental illness. Exploring the findings from the clinical side, there is still much social unacceptability, or stigma, of people with disabilities as parents; for example, it is "estimated that about 60 percent of mothers with chronic mental illness do not raise their own children” (Jacobsen \& Miller, 1997).

According to the National Institute on Mental Health (2010) about one in four adults in the United States (26.2\%) have a diagnosable mental illness. Yet, there is still stigma attached to a mental illness diagnosis. As previously mentioned by Garland, social relationships are key component of culture. These social relationships are what drive stigma. "Stigma represents a view of life; a set of personal and social constructs; a set of social relations and social relationships; a form of social reality” (Coleman Brown, 2010, p. 179). Therefore, anything that varies from the dominant culture view of life or set of ideals fuels stigma. Recently, there have been novels and films in which writers share their personal experiences with mental disabilities, a few of which have been praised by organizations for their potential impact on the general public to decrease stigma; for example, both "A Beautiful Mind" and "Canvas" were praised by the National Alliance on Mental Illness (NAMI). While these films offer a narrow glimpse into the lives of those living with mental illness, they can be instructive in thinking about popular understandings of people living with mental illness. For example, NAMI praised "A Beautiful Mind”; however, this was not the reaction from the disability community, which demanded a public apology from Universal Studios for the inaccuracies portrayed in the film about John Nash, who in real-life survived the worst consequences of schizophrenia and lived a full life without taking psychotropic drugs, opposite of what was stated in the film. This cinematic and literary phenomenon offers a glimpse into how mental illness affects familial relationships compared to in the past when having a family member with a mental illness would be something that was not openly discussed. While the ADA has improved the integration of people with disabilities into society, and many films have portrayed disabled and "mentally ill" characters, mental disabilities still remain a taboo topic. Common myths of people with mental disabilities and mental illness include but are not limited to them being viewed as deviant/violent, pitiful, a burden on society, non-sexual, or hypersexual and a threat to society (Rembis, 2011). These myths have had devastating effects in the past for people with disabilities by infringing on their reproductive rights, especially among women with disabilities. 
The rise of the eugenics movement in the late 19th century sparked inaccurate stereotypes of women with disabilities that still reverberate to this day (Dotson et al., 2003; Rembis, 2011). The main premise of the eugenics movement was to control who could reproduce in order to improve the human race as it was believed that heredity was responsible for disabilities. The eugenics movement painted women with disabilities as "unfit for procreation and as incompetent mothers" (Saxton, 2010, p. 122). This line of thought has contributed to other stereotypes, such as women with disabilities being dependent and asexual, or hypersexual and a threat to society and their children, which are still present to this day. During the eugenics movement these ideas provided the groundwork to take away disabled people's reproductive rights by involuntarily sterilizing tens of thousands of women with disabilities presumably to prevent the spread of their disabilities. Even though involuntary sterilization is now illegal, some women with disabilities are still subjected to having their reproductive rights violated by being surgically sterilized or provided birth control without their knowledge or without informed consent, which is reminiscent of the eugenics movement (Dotson et al., 2003). With 37 states using disability-related issues as reasons to terminate parental rights (Lightfoot et al., 2010), the ideals of the eugenics movement are still present despite the passing of the ADA.

Disability rights advocates have wholeheartedly disagreed with the eugenics movement. They believe women with disabilities have the right to bear children and be mothers (Saxton, 2010). These rights are currently supported under present laws and the Americans with Disabilities Act (ADA). The ADA was passed in 1990 to protect individuals with disabilities against discrimination. Title II applies to decisions made in the courtroom and other governmental agencies, which include child custody cases and termination of parental rights. Although the individual's disability status should not be a determining factor in such cases, it frequently appears to be, instead of the individual's parenting ability. This is depicted in the movie I am Sam, which will be discussed later in this paper. The stigma of having a disability equating to not being able to be a good parent appears to be at the forefront of the people involved in the parental rights court cases. Levy and Rubenstein (1996) found that "Many judges, social service officials, and even experts called to testify in these cases appear to share the same prejudices as the rest of society against allowing qualified parents with mental disabilities to keep their children” . Under Title II, state and local governments are required to make reasonable modifications. This means that "if the state is intervening in the parent-child relationship at least in part because of the parent's disability, it must take reasonable steps beyond those that are otherwise required by law to keep the family together and to provide supports for the parent” (Levy \& Rubenstein, 1996, p. 176). Such modifications would include parenting classes, homecare assistance, support groups, community resources, and counseling.

Currently, there is nothing in place to enforce and regulate the provisions laid out in Title II of the ADA. In addition, in order to be covered under the ADA, one must qualify under the ADA's definition of disability, which is "a physical or mental impairment that substantially limits one or more major life activities, a history or record of such an impairment, or a person who is perceived by others as having such an impairment” (USDOJ, 2002). Major life activities include both activities of daily living and instrumental activities of daily living. This definition may not apply to every individual who has a mental illness or disability diagnosis; therefore, challenging this definition so it encompasses all individuals with mental illness or disability is a must in order for all individuals with disabilities to be protected under the ADA.

\section{Role of Media}

The films “A Beautiful Mind”, “Canvas”, and "I am Sam” will be used to make points about parental rights. 
Films are used as reference points as they reach a mass audience. In 2008, approximately one billion people went to the movie theatre. This number does not include individuals who rent movies or refer to the newspaper to read the critique of movies. These two vehicles greatly influence the general public's perceptions. When the film topic is on mental disabilities, writers and filmmakers alike need to make sure they are accurately portraying the individual with a mental disability not to reinforce negative stereotypes.

The phenomenon of cinematic and literary portrayals of parents with disabilities has opened the door to society to peek inside the private lives of these families. While movies such as "A Beautiful Mind" and "Canvas" were praised by the National Alliance on Mental Illness (NAMI) for offering an authentic representation of schizophrenia, these movies also may reaffirm society's fears about people with mental illness' suitability as parents. For example, in the movie "A Beautiful Mind", which is loosely based on a biography of the same name about Nobel Prize winning mathematician John Nash, Nash stops taking his medication for numerous reasons but stated that he was unable to help with the child and could not see things like he could before . He is preparing to give his son a bath by placing him in the bathtub. He leaves the room believing that one of his hallucinations is watching the child, which depicts a potential life-threatening situation as the child almost drowns in the bathtub. This scene fuels the negative stereotypes of people with mental illness as unfit parents. But one must question the accuracy of this scene as 100 mental health advocacy groups claim this movie distorts the truth about John Nash . Was this scene simply to add a Hollywood dramatic spin? Doubtful that this question would enter a movie viewer's mind, the damage is most likely already done with the conclusion that individuals with schizophrenia should not be parents.

The movie "Canvas" was written and produced by Joseph Greco, based on his childhood. This movie is different from "A Beautiful Mind", as it does not depict an exceptional person with schizophrenia, like John Nash, but an ordinary family. However, even in this film there is a potential life-threatening situation as the mom, played by Marcia Gay Harden, “...has paranoid schizophrenia” and believes people are trying to break into her house, which results in numerous phone calls to the police to come check out the house. During one of her hallucinations, she has a box cutter in her hand; her husband is trying to calm her down and trying to tell their son to go back to bed. Their son does not go back to bed and while the husband is trying to get the box cutter from his wife, she cuts her son's arm. This incident results in the mother being involuntarily hospitalized. Even though the son was injured by the mother with schizophrenia, the mother is represented as being a good, caring, sometimes overprotective parent, throughout the movie. This movie is interesting as you are seeing the parent-child relationship through the adult son's view of his childhood as he is the writer and producer of the film, which he does not depict her as an unfit mother.

Unlike the previously mentioned two movies, "I am Sam" is not based on a true story. It is a fictional account yet it depicts a sad truth bringing to light a reality of the prejudices found within the court system and other governmental agencies. There are numerous synopses of the movie online. Sean Penn plays a character, Sam, who has a developmental disability. He works at a Starbucks while raising his daughter, Lucy, played by Dakota Fanning, with the assistance of his close friends, all of whom have disabilities. Lucy is an intelligent child who soon starts to hinder her academic progression resulting which is Lucy being removed from Sam's care and a parental rights court case to be held. There is a scene when Lucy does pretend she cannot read a word that her dad had trouble reading which acts as the catalyst for removing her from his care. However, Sam addressed this issue when it came up, like most parents would. The scene took place in Lucy's bedroom while she is reading from the book "Stellaluna". (Johnson \& Nelson, 2001) 
Lucy: How can we be so dif...dif...I don’t know that word.

Sam: Yes you do. It starts with a "d" -

Lucy: I'm tired.

Sam: I don't believe you.

Lucy: Are you calling me a liar?

Sam: Yes. Now read the word.

Lucy: (crying) No...I’m stupid.

Sam: No you're not.

Lucy: I don't want to read it if you can't.

Sam: It makes me happy. I'm happy hearing you read it.

He holds the book open for Lucy. Now Lucy, pushing through a mountain of resistance, reads. And reads beautifully.

Lucy: "Why are we different and so much alike?”

This and other encounters played out in the movie show that Sam is a good parent and do not warrant the removal of Lucy from Sam's care. The implementation of the PAT screening tool would have provided support of Lucy remaining in Sam's custody and against the placement of Lucy into the foster care system.

Even though this movie was fictional, it sparked debate over the issue of parental rights. The Michigan Daily has an article titled Sean Penn makes "I Am Sam" one special movie by Jenny Jeltes, which was published January 29, 2002. In the article, she writes, “...The only problem in I Am Sam is the doubt over the reality of it all. You may want to know if the film is based on a true story it seems quite likely. Because it is not, however, some situations seem very unrealistic, and they raise a lot of doubt. First of all, could a mentally handicapped man even be allowed to raise a child, especially when it was based on an accident? The question seems harsh, but it seems that today's legal system would have stepped in sooner to explore the issue". It is reactions like this that verify more education of the general public which is needed regarding individuals with disabilities. The portion of the author's question, “...when it was based on an accident” (Jeltes, 2002), is odd and of uncertain relevance considered there are statistics out there stating that one-third of pregnancies are accidents .

\section{Parent with a Mental Disability Court Case}

In an Iowa appellate court case, a father referred to as challenged the ruling of the termination of his parental rights for his three children. S.W.N. sustained a head injury in a car accident in which a portion of his frontal lobe was removed. In this court case, it stated that the father's mental disability was a factor in the determination "whether a child was neglected to the point where his or her interest and welfare required termination" and that rehabilitation was not possible. Yet, this is a direct violation of the ADA as "reasonable accommodations" were not provided. The court case does not elaborate on what neglectful actions the father has committed. The district court is quoted as saying, "He clearly loves his children, but he is not a good parent. His father has attempted to coach him regarding the handling of the children, but this has been with very limited results". This judgment should have been challenged solely on the grounds of what makes the "father" qualified to coach S.W.N.? This does not qualify as a "reasonable accommodation", S.W.N. should have been required to meet with a parenting coach to work on his parenting skills in order for the three children to have remained in the care of their father. 
The appellate court upheld the termination of parental rights because the three children were cognitively delayed and mentioned S.W.N.'s severe money problems. Money problems do not make him a bad parent as almost half of Americans live in debt. Similar to the movie "I am Sam", the intervention came because the children were experiencing cognitive delays, which could have been addressed if the court would have provided a reasonable accommodation of tutoring for the children and if needed, homecare assistance. The court ruled rehabilitation was not an option based on S.W.N.'s father's testimony, as stated previously, S.W.N.'s aunt, of whom he owed money which may have biased her testimony, a psychologist, who performed clinical assessments, and a social worker, none of whom provided or requested reasonable accommodations as required under the ADA, nor did the court justify how rehabilitation was not possible beyond S.W.N.'s father's testimony.

\section{Suggestion for the Courtroom}

Parental rights should be determined by the individual's parenting ability, but with all of the different assessment tools used to make this determination and the subjectivity of the assessor and judge, parental rights can be terminated based on prejudices. A study conducted by Jacobsen et al. (1997) tries to remedy this by developing a better and more comprehensive assessment tool for parents with severe mental illness called a Parenting Assessment Team (PAT). PAT is a comprehensive parenting assessment created in collaboration between the University of Illinois at Chicago, Department of Children and Family Services, and a community-based parenting rehabilitation program in response to some of the highly publicized cases of children who were killed by their mothers with schizophrenia after being returned home. This screening tool is important as the stigma about mental illness is that the individual with a mental illness is a dangerous and an unfit parent but this screening tool has the potential to suggest otherwise and that the child is not in immediate danger. A screening tool such as PAT should be a requirement in parental rights court cases and they are not.

PAT takes into consideration the risk factors and protective factors of child maltreatment. The methodological flaws found in other assessment tools were minimized in three ways: "(1) choosing diverse types of assessment tools, including several that elicit data directly relevant to parenting; (2) modifying existing tools to be relevant to the culture and socioeconomic background of the parents studied; and (3) cross-checking interview and self-report data with data from other sources”, such as police records, mental health records, and interviews of family, friends, and neighbors (Jacobsen et al., 1997, p. 193). PAT utilizes various assessment tools: Parent Opinion Questionnaire; Home Inventory; Parental Stress Index; pediatric records; developmental assessment of children; Social Support Inventory; interview of collaterals; Crittenden index of videotaped parent-child session; Expressed Emotion Scale; Structural Clinical Interview for DSM-III-R (SCID-R), record review; interview of therapist; urine drug screen; and Childhood Trauma Interview.

Each of these assessment tools provides a little piece of vital information; combined, they offer a comprehensive view of the individual and what their individual needs may be. The court system may want to endorse a more comprehensive screening tool like this based on individual cases so not all people with mental illness are lumped together as there was a proposal made to automatically terminate parental rights for parents with long-term mental illness (Jacobsen \& Miller, 1998). While PAT tries to find a better and more comprehensive screening tool for individuals with severe mental illness to help combat prejudices found within the court system and other governmental agencies, there needs to be something in place to educate the general 
population about parents with mental disabilities. One way to do this is through novels, film, and other media outlets.

\section{From the Courtroom to the Newsroom: Andrea Yates}

The author of The Michigan Daily article is not the only individual who has expressed the opinion that people with mental disabilities cannot be parents as the stigma about parents with mental illness, mainly focused on women, which was recently reinforced with the cases of Andrea Yates and Susan Smith among others. In fact, a website has been created: The Psycho Ex Wife: Read It and Weep "Top Psycho Moms: 10 of the Worst" . At the end of this list, the author offers the following: "I have a few thoughts: Ever notice how often child-killing mothers are excused for what they do? Ever notice how often child-killing mothers get the "female sentencing discount" for their grisly crimes. Do you ever wonder if the stats on domestic violence are skewed because mothers who kill their children or husbands or boyfriends are rarely, if ever categorized as "domestic violence" Sixty one percent of all child abuse is committed by biological mothers while only $25 \%$ is committed by biological fathers according to data available at the DHHS report on nationwide Child Abuse". The author of this website asks the question, "Do you ever wonder if the stats on domestic violence are skewed because mothers who kill their children or husbands or boyfriends are rarely, if ever categorized as "domestic violence" shows the need for clarification.

The statistics of mothers who kill their children would not be listed under the statistics of domestic violence as this is not incorporated under the definition of domestic violence; it falls under the statistics of child abuse and is reported. However, according to ChildHelp.org website (2011), the statistic is greatly skewed as up to $85 \%$ of child maltreatment fatalities are not recorded as such on death certificates. The definition of domestic violence, which has been replaced by intimate partner violence, is used to describe the violence that takes place between two people in a romantic relationship, which includes current and former partners (CDC, 2011). The statistics for women who kill their husbands or boyfriends would be captured under this definition. Death is the ultimate health consequence of intimate partner violence. According to the CDC (2011), there were 2,340 deaths resulting from intimate partner violence which $70 \%$ of these were female victims and $30 \%$ were male victims.

Since this website mentioned Andrea Yates, her case will be explored more in-depth. Andrea Yates was diagnosed with schizophrenia and depression. She is infamous for drowning her five children in the bathtub. The website "The Psycho Ex Wife" does not provide any details about Yates only the method by which she killed her children. Yates drowned her children believing that she was saving them from hell. Initially.Yates was found guilty as the prosecution made an argument that Yates' actions were an act of rebellion against her domineering husband (Donaldson, 2002). Donaldson (2002) points out "the defense's attempts to explain Yates's medical condition and the delusional systems of thought caused by her mental illness failed to convince the jury, which was most likely influenced not only by the argument that Yates was a rebellious woman, but also by the popular suspicions and misconceptions surrounding mental illness". The writer of "The Psycho Ex Wife" website seems to agree with the prosecution as he highlights the fact that her conviction was overturned in 2006 by reason of insanity, which as he believes excuses her from her actions. On the contrary, Yates is now getting the assistance she needs for her mental illness as she has been committed to a state mental hospital. If one's only knowledge of Andrea Yates came from "The Psycho Ex Wife” website, you would be missing the whole picture, questioning how a mother could do that to her children and then you learn she has a mental 
illness which would feed into the stigma of why individuals with mental illness should not be parents as the social relationship of the role of the parent as protector is missing. Yet, even though the Yates's situation is extremely unfortunate, she believed that she was acting as a protector, she had to "save them from hell" . If there could have been an early intervention point or resources available for Yates, this situation most likely could have been avoided.

\section{Baring It All: Media and Celebrity}

Recently, numerous celebrities have openly admitted to living with mental illness; for example, Catherine Zeta-Jones has publicly discussed living with bipolar disorder. However, the media has in the past inaccurately labeled celebrities as having a mental illness to explain their bizarre behavior; for example, Britney Spears. In 2007 and 2008, Spears was pictured on numerous magazine covers, such as Ok! Magazine and People, with the label "mental illness", with speculations ranging from bipolar disorder to schizophrenia. To date, Spears has not commented on being labeled as having a mental illness. These labels came after she filed for divorce from her husband, Kevin Federline, and ensuing custody battle. She shaved her head, attacked a car with an umbrella, and turned to alcohol and drugs while coping with these life changing events fueling the rumors of her having a mental illness.

In addition to these rumors swirling, the judge in her court case used the media coverage against her, even though the court records are sealed, MSNBC reported on October 1, 2007, that Judge Gordon ordered Spears to undergo random drug and alcohol testing the previous month as part of the custody battle with her ex-husband based on her "habitual, frequent and continuous use of controlled substances and alcohol". While the reasons for the termination of Spears' parental rights are contained in sealed court documents and have since been reversed, Spears was granted reasonable accommodations that are guaranteed under the ADA Title II such as meeting with a parenting coach weekly. Celebrities should not be the only persons afforded these rights. The ADA covers all people with disabilities, both physical and mental; therefore, more judges should grant reasonable accommodations for parents with disabilities not just celebrity parents with disabilities, or those labeled by the media with disabilities.

\section{Conclusion}

While new information is continuously being discovered about mental disabilities that assist in their understanding of the disabilities themselves, there is still stigma that needs to be battled. With the phenomenon of individuals sharing their experiences with mental disabilities through literature and film, the stigma attached to the different types of mental disabilities may begin to diminish. Being a parent is hard enough, being a parent with a mental disability has additional challenges but having a mental disability does not make the individual a bad or unfit parent. People with disabilities currently make up the largest minority group in the United States, representing approximately $19 \%$ of the U.S. population. This percentage is expected to increase as the population ages with the baby boomer generation, which represents an unique feature of this minority group, you can be a member if you have a congenital disability or an acquired disability .

The ADA should be enforced and its reach expanded to address the lack of supports for parents with disabilities. Such supports should include but are not limited to parenting classes, support groups, respite care, homecare assistance, increased knowledge of family and community resources, parent coaching, and counseling services. People given the task of enforcing the ADA do not currently provide these services or 
referrals to agencies that do, creating a website with all available resources for individuals with disabilities would be beneficial. One thought would be to create an ADA Compliance Officer position in the court system and other governmental agencies to ensure that the individual's rights are being upheld, especially in regard to reasonable modifications. Another idea would be to start a program similar to CASA (Court Appointed Special Advocate) which is for abused and neglected children to provide advocacy services for individuals with disabilities in the courtroom. An advocacy program of legal services should be developed to ensure that a parent's rights are not being terminated based solely on disability status, thus, being in direct violation of ADA Title II.

\section{References}

Canvas (2006). NAMI review. Retrieved from http://www.canvasthefilm.com/press/nami.pdf

CDC (2011). Understanding intimate partner violence. Retrieved from http://www.cdc.gov/violenceprevention/pdf/IPV_factsheet-a.pdf

Childhelp (2011). National Child Abuse Statistics. Retrieved from Website: http://www.childhelp.org/pages/statistics

Coleman Brown, L. M. (2010). Stigma: An Enigma Demystified. In L. J. Davis (Ed.), The Disability Studies Reader (pp. 179-192). New York: Routledge.

Donaldson, E. J. (2002). The Corpus of the Madwoman Toward a Feminist Disability Studies Theory of Embodiment and Mental

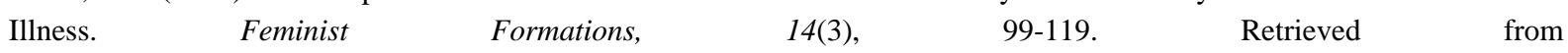
http://muse.jhu.edu/journals/ff/summary/v14/14.3donaldson.html

Dotson, L. A., Stinson, J., \& Christian, L. (2003). “People Tell Me I Can’t Have Sex”: Women with Disabilities Share Their Personal Perspectives on Health Care, Sexuality, and Reproductive Rights. Women \& Therapy, 26(3/4), 195-203.

Emax Health (2007). One-Third Of Pregnancies In America Are Unwanted. Retrieved from Website: http://www.emaxhealth.com/89/11909.html

Hubbard, R. (2010). Abortion and Disability: Who Should and Should Not Inhabit the World? In L. J. Davis (Ed.), The Disability Studies Reader (pp. 107-119). New York: Routledge.

Jacobsen, T. \& Miller, L. J. (1998). Focus on Women: Mentally Ill Mothers Who Have Killed: Three Cases Addressing the Issue of Future Parenting Capability. Psychiatric Services, 49(5), 650-657. Retrieved from http://psychservices.psychiatryonline.org/cgi/content/full/49/5/650

Jacobsen, T., Miller, L. J., \& Kirkwood, K. P. (1997). Assessing Parenting Competency in Individuals With Severe Mental Illness: A Comprehensive Service. The Journal of Mental Health Administration, 24(2), 189-199.

Jeltes, J. (2002). Sean Penn makes "I Am Sam" one special movie. The Michigan Daily. Retrieved from http://www.michigandaily.com/content/sean-penn-makes-i-am-sam-one-special-movie

Johnson, K. \& Nelson, J. (2001). Screenplay “I am Sam” Shooting Draft. Retrieved from http://www.weeklyscript.com/I\%20AM\%20Sam.txt

Levy, R. M. \& Rubenstein, L. S. (1996). The Rights of People with Mental Disabilities. USA: American Civil Liberties Union.

Lightfoot, E., Hill, K., \& LaLiberte, T. (2010). The Inclusion of Disability as a Condition for Termination of Parental Rights. Child Abuse \& Neglect, 34(12), 927-34.

Media by Numbers, LLC. (2009). Year-to-Date Box-Office Attendance. Retrieved from Website: http://www.mediabynumbers.com/userfiles/file/MEDIA\%20BY\%20NUMBERS\%20HISTORICAL\%20AND\%20YTD\%20 BOX-OFFICE\%20-\%202008b(1).pdf

National Institute of Mental Health (2010). Statistics: Any Disorder Among Adults. Retrieved from http://www.nimh.nih.gov/statistics/1ANYDIS_ADULT.html

Rembis, M.A. (2011). Defining Deviance: Sex, Science, and Delinquent Girls.USA: University of Illinois Press. Retrieved from Website: http://www.cbsnews.com/stories/2006/07/26/national/main1837248.html

Saxton, M. (2010). Disability Rights and Selective Abortion. In L. J. Davis (Ed.), The Disability Studies Reader (pp. 120-132). New York: Routledge.

Straus, J.N. (2010). Autism as Culture. In L. J. Davis (Ed.), The Disability Studies Reader (pp. 535-559). New York: Routledge.

The Psycho Ex Wife. (2009). Top Psycho Moms: 10 of the Worst. Retrieved from http://www.thepsychoexwife.com/top-psycho-moms-10-of-the-worst/ 
U.S. Department of Justice. (2002). Title II Highlights. Retrieved from http://www.ada.gov/t2hlt95.htm

U.S. Department of Justice. (2005). A Guide to Disability Rights Laws. Retrieved from http://www.ada.gov/cguide.pdf 